\title{
1. International trade and transportation: an introduction
}

\author{
Bruce A. Blonigen and Wesley W. Wilson
}

\subsection{INTRODUCTION AND CONTEXT}

Over the last several decades, international trade has grown at a phenomenal rate. Transportation has also substantially changed in ways that may have not only accommodated growth in world trade, but also helped spur it. There have been a number of major technological and structural changes in the transportation of goods between countries. These include the introduction and growth of containerization, the development of supersized ocean ships and the subsequent development of ports to accommodate these ships, the increasing growth of air transportation of goods, and, more recently, growing attention to the environmental consequences of trade and policies. While the connection between transport and international trade is clear, the academic literature has often looked at these two issues separately. This chapter introduces the Handbook of International Trade and Transportation, which brings together contributions from leading experts to highlight what we know about the intersection of these topics and ideas for future research in this relatively unexamined area of study.

Since the early 1960s, world GDP and trade have each grown substantially (Figure 1.1),

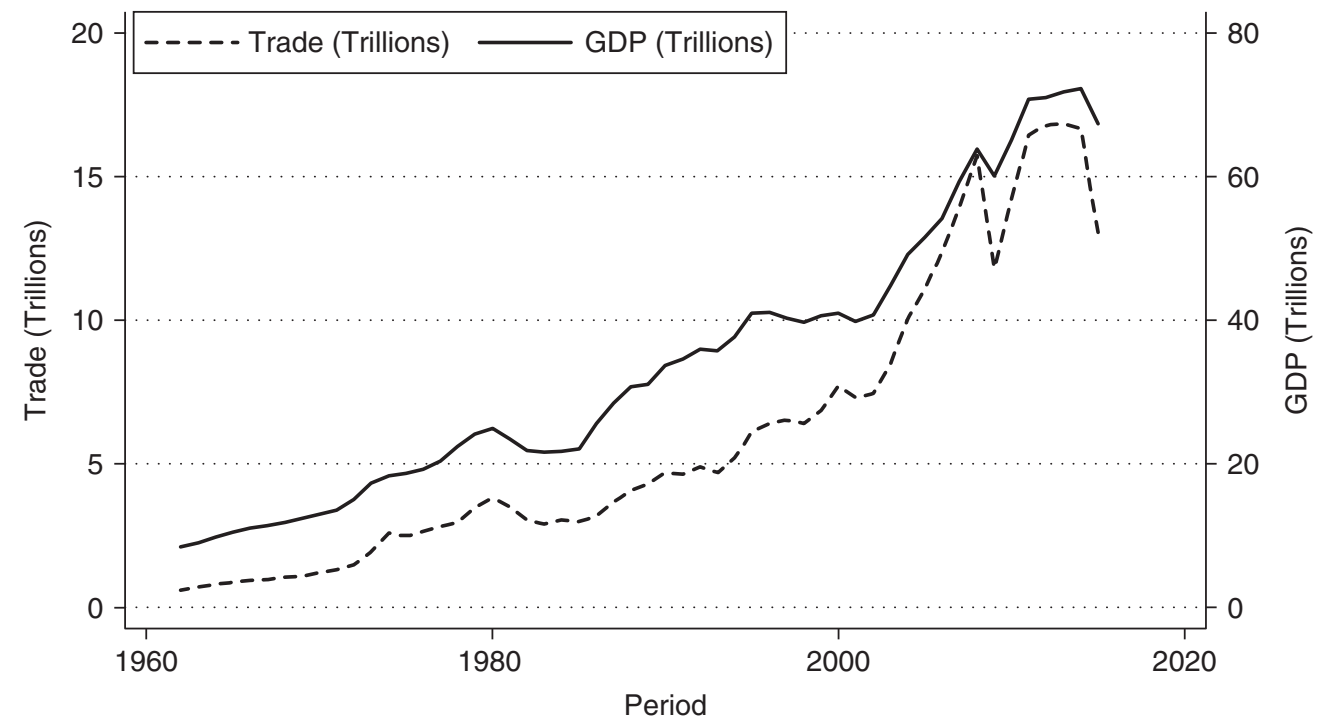

Note: In 2009 dollars.

Figure 1.1 Trade and world economies 


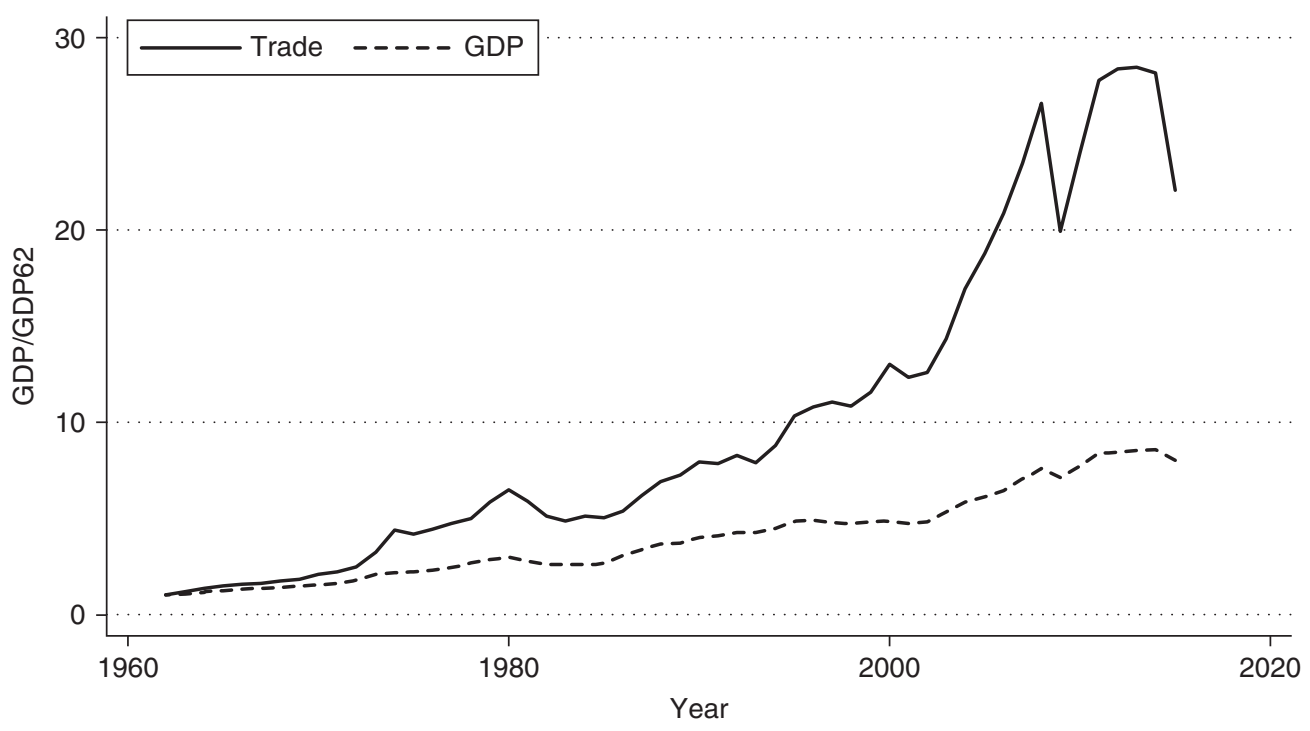

Figure 1.2 Trade and GDP relative to 1962

with increases in virtually every year except for the recessions in 1982 and 2009. As shown in Figure 1.2, trade has substantially outpaced the growth in the world GDP. While world GDP has grown by a factor of nearly 10 since the early 1960s, trade has grown by a factor of nearly 30 in that time.

As shown in Figure 1.3, the composition of trade has also changed markedly over time. Over the years, trade between OECD (developed) countries has typically constituted a majority of world trade. However, for the past couple of decades this share has been steadily declining and was down to about 30 percent in 2015 . The fall is largely explained by the growth in trade between and with non-OECD countries, especially the rise of China in the world economy.

There have also been substantial innovations in transportation that has not only accommodated the growth in world trade, but has also provided for an additional source of growth. The introduction of containers in the 1950s was a significant innovation in waterborne transport, leading to large improvements in efficiency. It also spurred major investments in infrastructure and vessels to realize even further gains from the innovation. As shown in Table 1.1, containers accounted for about 102 million tons (about 8.3 percent of container and other dry cargo) in 1980, but had reached nearly 1687 million tons (about 40.7 percent of container and other dry cargo) by 2015 . This is over a 16 -fold increase in containerized goods, with an annual growth rate of 11.9 percent.

In addition, there has been an increase in transportation by air over time, which was virtually non-existent in the early 1970s. In 1973, only 15568 million ton-km of goods were carried by air transport, while over 195000 million ton-km were carried in 2016, a 12-fold increase (World Development Indicators). And, as noted in Cristea et al. (2013), while transportation by air remains small in terms of weight (about 1 percent), it has become sizable in terms of value (about 18 percent of total trade). 


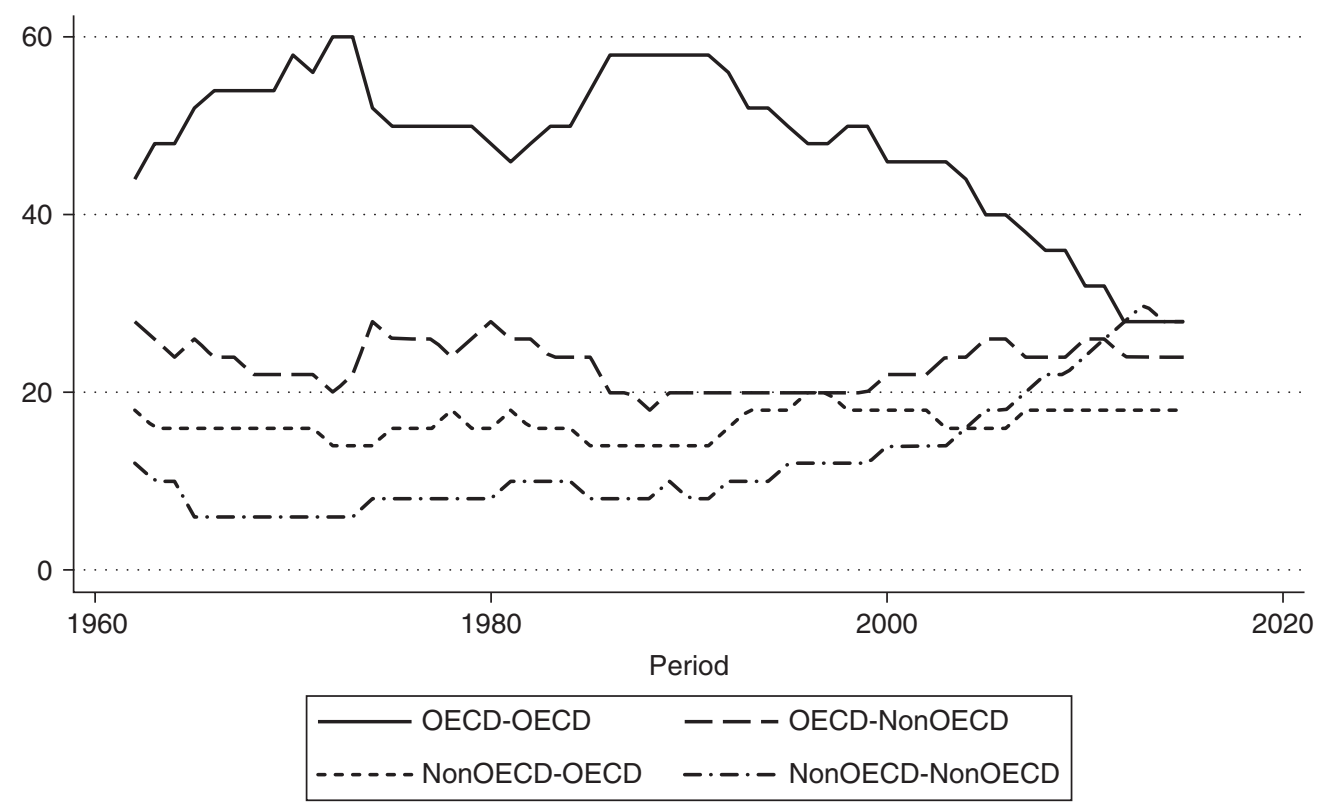

Note: Showing percentage of world trade.

Figure 1.3 Imports by OECD and non-OECD countries (1993 members)

Table 1.1 International seaborne trade

\begin{tabular}{lcccc}
\hline Year & Container & Other dry cargo & $\begin{array}{c}\text { Main bulk } \\
\text { commodities }\end{array}$ & Oil and gas \\
\hline 1980 & 102 & 1123 & 608 & 1871 \\
1985 & 152 & 819 & 900 & 1459 \\
1990 & 234 & 1031 & 988 & 1755 \\
1995 & 371 & 1125 & 1105 & 2050 \\
2000 & 598 & 1928 & 1295 & 2163 \\
2005 & 1001 & 1975 & 1711 & 2422 \\
2010 & 1280 & 2022 & 2335 & 2772 \\
2015 & 1687 & 2463 & 2951 & 2947 \\
2015 share & 0.17 & 0.25 & 0.29 & 0.29 \\
Annual growth rate & $11.9 \%$ & $3.2 \%$ & $6.5 \%$ & $1.8 \%$ \\
\hline
\end{tabular}

Notes:

Amounts in millions of tons loaded.

Main bulk commodities are iron ore, coal, grain, alumina and bauxite, and phosphate rock.

Source: UNCTAD, Review of Maritime Transport (various issues). 


\subsection{THE ACADEMIC LITERATURE AND NEED FOR THIS HANDBOOK}

Naturally, analysis by the academic literature has burgeoned along with the rapid integration of the global world economy. But, while the connection between transport and trade flows is clear, the literature often looks at these two issues (international trade and transport) separately. International trade theory often models trade frictions between countries as general costs that lump transport costs with other trade frictions, such as communication costs, regulatory costs, and even border taxes. In empirical work by international trade economists, distance between countries often proxies for transport costs, but could also be proxying for a whole host of these other trade frictions. At the same time, the transport literature rarely worries about whether the goods being transported are crossing international borders and whether this raises interesting issues for the transport sector that would not be faced for domestic transport.

The record of rapidly expanding trade over the past half-century and the transport sector's growth to meet this demand is impressive. At the same time, there is concern for the future of global integration as we write this. First, trade growth has flattened a bit in recent years. Second, the public and politicians in many countries are becoming much more skeptical about having their borders so open to international trade and other forms of integration. The vote of the United Kingdom (U.K.) to separate from the European Union (commonly referred to as Brexit) was an unexpected blow to European integration, and there continue to be concerns about whether the European Union will further unravel as a result of this and other stresses, such as the debt crisis in some of its less rich partner countries. While immigration issues seemed to be a prime motivator for Brexit, it certainly could have significant adverse consequences for trade between the U.K. and the EU, as well as other related trade flows.

Relatedly, the role of trade (and immigration) in rising income inequality in other parts of the world is causing great concern about global integration and calls to slow it down or even reverse it. In the United States, President Trump immediately stopped negotiations for the Trans-Pacific Partnership and indicated that he would renegotiate the North American Free Trade Agreement. ${ }^{1}$ The possibility of a Transatlantic Trade and Investment Partnership (TTIP) between Canada, Europe, and the United States is likewise spurring significant protest movements, and its prospects are uncertain. ${ }^{2}$

\subsection{PLAN OF THE HANDBOOK}

This Handbook is expressly meant to pull together the key insights of each of the literatures (international trade and transport), while highlighting what we know about the intersection of these topics and ideas for future research in this relatively unexamined area of study. There are two main audiences we hope will most benefit from this endeavor. The first are current scholars who may have their primary expertise in one of these literatures, but are not as familiar with the other. The chapters related to the topics less familiar to

1 His initial actions as President toward immigration were equally, if not more, dramatic.

2 See, for example, http://www.reuters.com/article/us-eu-usa-ttip-idUSKCN11N0H6. 
them should give them an excellent primer on the essential concepts and references for the topic. This should likewise be useful to new scholars in these literatures - advanced undergraduate students, graduate students, and other researchers who are relatively new to the field.

The structure of the Handbook is as follows. It begins in Part I with chapters that present the latest data and modeling techniques used to explain global trade patterns. The initial chapter of Part I, "Gravity, distance, and international trade" (Chapter 2), by Scott L. Baier, Amanda Kerr, and Yoto V. Yotov, beautifully lays out the gravity trade equation, the fundamental empirical specification in the international trade literature that so robustly explains trade patterns between regions and countries in the world. Although it was once thought to be an atheoretical empirical coincidence, Baier, Kerr, and Yotov's chapter rigorously lays out the trade theory that grounds the gravity relationship in international trade patterns and derives the structural gravity empirical specification that is at the forefront of estimating empirical international trade patterns. Their chapter further provides a variety of useful extensions to the model, including accounting for endogeneity, internal (national) flows of goods, and missing or zero trade flows. Finally, they provide an example of the power of structural gravity estimation in its natural ability to provide theory-grounded counterfactual simulations, showing two examples, including the potential effects of a free trade agreement (FTA) between the U.K. and the U.S.

The next chapter in Part I, "International trade data and empirical patterns" (Chapter 3), by Peter H. Egger and Yvonne Wolfmayr, is an excellent complement to Chapter 2 by providing a detailed and thorough accounting of the available international trade data needed for estimation. Such data come from many national statistical agencies that are further refined by a number of different supranational organizations. Egger and Wolfmayr do a masterful job of reconciling the differences in reported international trade data and then documenting when and where it may matter for empirical inferences. This chapter serves not only as an excellent reference for novices wishing to begin work with international trade data, but also as an insightful analysis of the nuances of measurement issues in these data for the experienced researchers in the field.

The final chapter of Part I is "Gravity models in air transport research: a survey and an application" (Chapter 4) by Yahua Zhang, Faqin Lin, and Anming Zhang. The gravity relationship has been found to be a robust representation of a wide variety of international economic patterns, including not just goods flows, but also capital flows. This chapter uses the recent state-of-the-art gravity model specification to examine both air cargo and passenger traffic in Chinese air transport activity. In doing so, the chapter shows the robustness of the gravity equation for estimating international activity, as well as its efficacy as a framework for evaluating the effects of transport policies.

With this initial context in place, Part II is a group of chapters addressing the core theme of the Handbook: the intersection of international trade and transportation costs. Chapter 5, "Trade costs and international trade flows: methodologies, data, and empirical evidence" by Michael O. Moore, sets the stage with an excellent overview of this literature from an international trade economist's perspective. The international trade literature has often treated transport costs as a black-box friction in its theoretical models. Likewise, empirical work in international trade economics will often use crude proxies for transport costs, such as the distance term in a gravity model. As such, transport costs have rarely been the focus of analysis. Moore's chapter surveys this landscape and especially points 
to more recent analyses that have begun to focus on the issue in more detail and possible future directions. In many ways, Moore's chapter confirms the need for more work in this area, which this Handbook hopes to spur.

A major factor limiting rich analyses of transport costs and their effect on trade is the paucity of detailed transport cost data. Chapter 6, "Transport costs, trade, and geographic concentration: evidence from Canada" by Kristian Behrens and W. Mark Brown, is a study that portends the exciting future of this literature as scholars access better and richer data on transport costs. Behrens and Brown look at the relationship between trade and transport costs using a new database on transaction-level trucking rates between Canadian regions and Canada-U.S. truck shipments, which they match to geocoded plant-level data. Such rich, precise data allow them to more accurately estimate the elasticity of trade flows with respect to transport costs and (relatedly) the relationship between distance and transport costs. The latter relationship is an important one that critically depends on the extent to which there are fixed versus ad valorem costs of transport as distance increases. Their empirical evidence suggests transport elasticities of trade that are significantly different than those used by previous studies. Their geocoded plant-level information also allows them to examine the effect of transport costs on the geographic concentration of plants in Canada, finding perhaps some of the first convincing evidence that transport costs have a significant impact on geographic concentration. The study not only provides interesting new results owing to the rich micro-data used, but also has a welldesigned theoretical model to situate its empirical work and provides creative strategies to control for endogeneity of transport costs and trade. It is an important study that shows the exciting path forward in the literature.

A large driver of the rapid increase in world trade has been the surge in the phenomenon of offshoring - sourcing intermediate inputs from abroad. In some industries, it has become common to break up their manufacturing process into a global production chain across many countries to lower costs. Such an organizational strategy can only be pursued with low enough transport costs between locations, and the decline of transport costs is likely a major factor in the rapid rise of offshoring. As with many international trade phenomena, measuring the extent to which it has occurred, much less how much transport costs have been fundamental to this transformation, is not simple. Chapter 7 , "Offshoring and transport costs" by Holger Görg and Aoife Hanley, provides an excellent overview of the literature on this important topic at the intersection of international trade and transport costs. After a thorough discussion of data and measurement, the chapter takes us through the evolution of theoretical developments in the literature over time through the most recent models. With the theoretical context set, the last third of the chapter reviews the empirical literature, with a particular focus on studies examining the role of transport costs.

A topic that has intrigued scholars on both sides of the intersection of international trade and transportation is the famous Alchian-Allen theorem. The exact nature of how transport costs vary with distance can have a number of surprising consequences. The Alchian-Allen hypothesis is that transport costs have a significant fixed per-unit cost component that is independent of the value of the good, which will lead the relative price of high-value (i.e., high-quality) products to decline more sharply with distance. Thus, we will see a great proportion of higher-quality versions of a product in more distant markets, a phenomenon sometimes referred to as "shipping the good apples out." Chapter 
8, "Transportation costs and trade for differentiated agricultural products" by Dragan Miljkovic, reviews the extensive theoretical literature on the conditions under which the Alchian-Allen theorem holds and then provides a more rare empirical examination of the theorem using detailed data on Japanese beef imports.

The final chapter in Part II, "Environmental issues in international trade and transportation" (Chapter 9) by James J. Corbett and James J. Winebrake, examines an issue of increasing concern for transportation of internationally traded goods - environmental costs. The chapter provides a thorough primer on the many ways in which international transport can have environmental impacts, as well as the evolution of policy in this arena and responses by shippers in response to these policies. It concludes by describing a number of innovative practices that could help transport reduce environmental costs, including optimal steaming speeds, new ways of intermodal connection, and synchronizing supply chains. The potential for analyzing the efficacy of these strategies and related consequences in the future is substantial.

Traditional models of international trade focus on cross-country or cross-region trade patterns. But countries don't directly trade with each other; firms and individuals do. The next two parts of the Handbook explore the micro-foundations of international trade and transport, with Part III reviewing what we know about the agents that are responsible for international trade transactions, and Part IV examining how those agents negotiate the logistics of transporting goods across international borders.

The primary agents responsible for international trade transactions are firms. In the last 30 years, international trade economists have developed important new models of trade that are micro-founded in firm-level decisions. At the same time, there has been a relative explosion of firm- and plant-level data that has become available to researchers to empirically examine the role of firms in international trade. This new literature is comprehensively examined in Chapter 10, "Firms in international trade" by Federico J. Díez, Jesse Mora, and Alan C. Spearot. The chapter first surveys the empirical facts that distinguish firms that export from firms that don't. Matching these facts has been key to refining our models of firms in trade over time, which the authors beautifully highlight as they review the evolution of theoretical models of firms in trade, beginning with the seminal contribution of Paul Krugman in 1979. Unlike other pieces that have surveyed this literature, the chapter pays special attention to the modeling of transport costs in each of these models in keeping with the theme of this Handbook. And Díez, Mora, and Spearot elegantly explain many extensions of these models, from considering multiproduct firms to learning by exporting effects to the role of finance in export decisions.

The role of firms in international trade can be much more complicated than simply that of direct exporter. Two key roles are as an intermediary of trade between two other parties and as a multinational firm that has invested in production assets in multiple countries (i.e., foreign direct investment). The next two chapters address the literature examining these more complicated roles. In Chapter 11, "Trade costs and the role of international trade intermediaries" by Bernardo S. Blum, Sebastian Claro, and Ignatius J. Horstmann, we first get a fascinating picture presented of how much intermediary firms are involved in trade flows (25-45 percent of all imports and 10-15 percent of all exports) and the types of products they handle. The many empirical facts the authors provide about intermediaries is then a jumping-off point for beginning to understand why there is a role of intermediaries - and this can be quite different for import intermediaries versus export 
intermediaries! The authors provide simple models to explain the role of intermediaries and draw out how transport and other trade costs can affect these roles and the prominence of intermediaries in trade. This is clearly a very nascent literature, and the authors have provided an intriguing review.

There is a much more established literature on multinational firms, which are key drivers of international goods and capital flows in the global economy. In Chapter 12, "Transportation cost and the geography of foreign investment," authors Laura Alfaro and Maggie Xiaoyang Chen provide an excellent examination of the role of transportation costs in determining where multinational firms have located their productive assets. Alfaro and Chen have been key contributors in a literature that examines the spatial distribution of multinational affiliates across the world and so are uniquely suited to review and explain this literature and the empirical evidence for how transportation costs and other frictions (such as information frictions) affect where multinational firms locate. Impressively, Alfaro and Chen have access to rich and comprehensive data on affiliates across the world, and they use these data in their analysis to illustrate the empirical evidence for the theory and hypotheses in the literature.

The nuts and bolts of crossing borders to trade goods internationally are not simple. Part IV addresses the issues that agents face in the logistics of moving goods in the global economy. Chapter 13, "Trade logistics and seaborne transportation" by Wayne K. Talley and Sara Russell Riggs, provides a superb overview of the bureaucracy that seaborne international trade logistics faces, as well as recent initiatives and policies by countries to ease this burden. The chapter then derives a model of seaborne trade costs that explicitly accounts for various logistics required in the face of existing bureaucratic policies, highlighting the additional costs faced by international shippers vis-à-vis domestic shippers.

Chapter 14, "Transportation and trade interactions: a trade facilitation perspective" by Jerónimo Carballo, Georg Schaur, and Christian Volpe Martincus, focuses on the recent global policy efforts to facilitate less bureaucracy and greater ease of shipping goods across international borders, as witnessed by the Trade Facilitation Agreement reached by the World Trade Organization in Bali in 2013. The literature examining these frictions and their effect on trade is relatively new however. The authors have been part of a massive data collection and analysis effort of border and customs transactions in Latin America. This rich data has allowed them to write some of the key papers in this literature and makes them perfectly suited for this chapter. After surveying the literature, they also provide novel analysis of how a major policy change to substantially reduce paperwork and wait times for trucks crossing international borders in Central America affected freight rates. Their analysis does not find a reduction in freight charges as one might expect (possibly owing to significant demand increases in the face of market power in the trucking industry), pointing out the interesting areas of study for future research.

The quality of the transportation infrastructure is critical if countries are to trade goods with each other. Part V addresses the literature that examines the quality and efficiency of infrastructure and its effects on international trade. The workhorse methodology for the transportation industry to study efficiency of transport infrastructure and systems has been data envelopment analysis (DEA). Kevin Hyosoo Park and Young-Tae Chang provide an outstanding primer on this methodology in Chapter 15, "DEA and transportation efficiency," including the most recent advances from network DEA to bootstrap DEA. Throughout, the chapter provides the reader with references to key DEA studies 
of critical transport infrastructure from ocean ports to airports. The authors conclude by describing analyses that infer contributions of various factors to DEA efficiency scores via statistical regression analysis.

Bruce A. Blonigen and Wesley W. Wilson examine the main infrastructure component for seaborne international trade - ocean ports - in Chapter 16, "Trade costs, trade, and port efficiency." Measuring ocean port efficiencies is not simple, as there is a lack of detailed, consistent data across ports, and most measures that are available tend to be case specific. Ports also often differ significantly in the types of goods and ships they handle. There have been two main ways to traditionally analyze port efficiency - DEA analysis and surveys - and Blonigen and Wilson first review these methodologies and related literature. While these studies can be relatively complex in terms of analysis, they also tend to be case specific and, therefore, do not provide the comprehensive measures needed for analysis of trade. Building off of prior work, Blonigen and Wilson introduce a different way to estimate port efficiencies using statistical analysis of international trade data, which provides a comprehensive ranking of updated port efficiencies for all the major ocean ports in the world. They show that these rankings have a strong positive correlation with international trade flows and compare their port rankings with those derived by other methodologies, such as DEA and surveys.

In Chapter 17, "Getting port governance right," Peter de Langen and Periklis Saragiotis point to the role of infrastructure governance and the role of ports for economic development. Historically, ports have been government owned and, indeed, continue to play a central role. However, in the past few decades privately owned terminal operating companies have emerged and contribute to more efficient supply changes. De Langen and Saragiotis describe the characteristics and economic rationale of a governance structure wherein the port authority operates as a port development company within an appropriate regulatory framework. They find that many countries are restructuring the way their port structures are organized. They point to specific cases where fully private or government owned is the appropriate outcome. The chapter is quite timely and pertinent given the pressure on ports for greater efficiency and to assess the current trends in restructuring.

Another key piece of infrastructure is the ships that transport internationally traded goods. Unlike ocean ports, which are often publicly funded, ships are costly investments for firms. In Chapter 18, "Vessel size, investments and trade," authors Lixian Fan, Xinlu $\mathrm{Li}$, Sijie Zhang, and Zimeng Zhang first provide a portrait of the various types of vessels transporting goods internationally and the evolution of basic demand and supply factors for ocean transport vessels. They then build an empirical demand and supply model to investigate the factors that affect investments in shipping vessels. As their study points out, the critical nature of vessels in international trade, the major innovations in shipping size in recent decades, and the complicated dynamic nature of investment in these markets point to the need for further research on this interesting topic.

The final part of the Handbook, Part VI, features chapters examining the network attributes of the international transportation system. The exact spatial aspects of a system of trade routes (formed by geographic features, policy, and other factors) have major implications for key issues, including the efficiency of trade flows and the equity of service across all nodes of the network. Theo Notteboom's chapter, "Trade and transport modes: the search for global connectivity through transport networks" (Chapter 19), begins Part VI with an excellent conceptual review of the many layers that compose the global trade 
network that exists today, including both international and domestic transport systems. The review not only is comprehensive over different modes of transportation, different types of transport, and international policy differences, but also gives a critical analysis of the more complicated and fragile parts of the current system and where the network may go in the future.

Peter O’Neill's chapter, "Benefits, challenges and trends for regional transport connectivity in Asia" (Chapter 20), is a nice complement to the Notteboom chapter in that it gives an overview of creating a transport network from a regional perspective (in this case, Asia). He provides a detailed review of the many issues that go into planning and building transport networks, including understanding economic trends and goals, investing in not only "hard" investments (e.g., roads) but also "soft" investments (e.g., organizations and agencies to oversee and maintain the hard investments), and concerns about equity and serving more rural regions. Overall, the chapter gives an interesting perspective on the many factors that face policy makers and planners as they drive the creation and expansion of transportation infrastructure.

Transportation networks are only as strong as their key links. The next two chapters provide insightful case studies of two interesting and important links in the global transportation network. The first is Chapter 21, "Euro-Asian overland transport links: prospects and challenges" by Miroslav N. Jovanović, Jelena Damnjanović, and Jovan Njegić, which explains the recent activity and investments to build up a new "Silk Road" between Europe and Asia. The authors detail how the overland route from Asia to Europe (the Silk Road) was long ago the primary transportation route between the two regions, primarily to get silk and other Asian goods to Europe. The rise of maritime connections made this route nearly obsolete. But, since 2002, a United Nations effort has aimed to re-establish this overland route - this time for the very different purpose of linking poorer landlocked Asian regions to the global transport network to spur economic development. The chapter provides an interesting view into the many challenges facing the project, from organizational to legal to technological (e.g., different-gauge railways that need to be linked).

The second case study chapter of a major link in the global transportation system is "Panama Canal" by William W. Wilson and Javier D. Ho (Chapter 22). The Panama Canal was originally completed in 1914 and allows a major bypass to shorten the seaborne routes of ships between Asia and the east coast of the United States. Wilson and Ho provide a fascinating historical review of the use of the Panama Canal over the years to the present expansion, which was just completed in 2016. The second half of the chapter delves into the competitive challenges facing the Panama Canal, including the need for further costly work to accommodate the ever-larger ships and competitive challenges from the Suez Canal. The chapter highlights the interdependence of any one link in a network and the dynamic (economic) changes that can occur to substantially change the use of a particular link.

Activity on various links of the global transportation network depends on economic forces, including the price charged for using the link. The level of competition is critical for pricing, and the shipping industry has a long history of shipping alliances and conferences or cartels that may keep prices artificially high. Chapter 23, "Competition and the container liner shipping industry" by Hilde Meersman, Christa Sys, Eddy Van de Voorde, and Thierry Vanelslander, provides an in-depth look at this issue for the container liner 
shipping industry, which is a major segment of ocean transport. The chapter begins with a review of the literature on shipping alliances and the evidence for their efficacy in the industry. This sets the context for a comprehensive review of pricing, concentration, and other market outcomes in the container liner shipping industry over the past decades.

\section{REFERENCES}

Cristea, A., D. Hummels, L. Puzzello and M. Avetisyan (2013), 'Trade and the greenhouse gas emissions from international freight transport', Journal of Environmental Economics and Management, 65 (1), 153-73.

Krugman, Paul R. (1979), 'Increasing returns, monopolistic competition, and international trade', Journal of International Economics, 9 (4), 469-79. 
Bruce A. Blonigen and Wesley W. Wilson - 9781785366154 